\title{
Thermoset composites reinforced with recycled cotton textile residues
}

\author{
Welton Fernando Zonatti", Bárbara Maria Gama Guimarães, Wânia Duleba and Júlia Baruque Ramos
}

\begin{abstract}
The recycling of textiles is an issue that requires immediate attention in order to address the management of textiles derived from household waste, as well as scraps generated throughout manufacturing textile processes. The present study aimed to produce composites employing three different types of thermoset resins (epoxy, polyester orthophthalic and polyurethane) reinforced with recycled cotton textile residues on which tensile tests were carried out. The incorporation of $30 \%(\mathrm{v} / \mathrm{V})$ of textile reinforcement in composites made from the specific epoxy resin employed in the present study showed an increase of approximately 2 -fold relative to pure resin tenacity and Young's modulus (respectively from 0.09 to $0.16 \mathrm{MPa}$ and from 0.5 to $1.2 \mathrm{MPa}$ ). For composites made of orthophthalic polyester resin, an increase was observed of 2-fold relative to pure resin tenacity and 3-fold relative to Young's modulus (respectively from 6.5 to $13.8 \mathrm{MPa}$ and from 193 to $772 \mathrm{MPa}$ ). No significant alterations were observed for these parameters in polyurethane resin composites (16 MPa for tenacity and near $700 \mathrm{MPa}$ for Young's modulus) probably because the modulus value supplied by the fraction of cotton fiber is not as significant as that one from the pure polyurethane resin. Two propositions of fashion accessories were made by employing these composite materials. Also, the artworks of renowned Brazilian designers, namely, Campana Brothers and R. Sobral, were analyzed to develop the artwork of such accessories for the present "documentation process". Thus in the present study aesthetic and technical aspects are analyzed together covering all production phases of material, processes, creation and design of final product.
\end{abstract}

Keywords: Composite; Thermoset resin; Recycled cotton residues; Sustainable design; Fashion

\section{Background}

In Brazil large amounts of textile clothing (often in good conditions) are being discarded along with scraps and textile virgin residues originated by apparel confection industries. Through enticing advertisements in virtual media such as newspapers, magazines, Internet and especially television, fashion can generate new aesthetic needs and desires.

According to a survey by MDIC - Brazilian Ministry of Development, Industry and External Trade, and ABIT Brazilian Association of Textile and Apparel Industry (2011), carried out in 2010, television was pointed as the major medium of fashion dissemination by $72 \%$ of respondents. Furthermore, $47.5 \%$ of them have already bought fashion products as a consequence of watching advertisements. Thus, consumption is stimulated, offering the false

\footnotetext{
* Correspondence: welton@usp.br

University of São Paulo, School of Arts, Sciences and Humanities, Av. Arlindo Béttio, 1000, 03828-000 São Paulo, Brazil
}

satisfaction of desires by the continued purchase of goods. Added to this strategy of the fashion industry, there is also planned obsolescence (Queiroz 2003; Broega et al. 2011, in which the life of a textile is related to a predetermined period of time, being discarded after this period - often in good conditions - indiscriminately by consumers.

On the other hand, there are also large amounts of scraps and textile residues originated by apparel confection industries. In Brazil, there are many regions with intense confection activity, mainly in the states of São Paulo, Santa Catarina and some parts of the Northeast region of the country. According SINDITEXTIL - Union of Spinning and Weaving Industries of the State of São Paulo - Brazil (2012), Brazil produces 175,000 ton of residues from the textile industry per year. In São Paulo city (São Paulo state, Brazil), approximately 10 ton per day (in the neighborhood of Brás) and 16 ton per day (in the neighborhood of Bom Retiro) of textile residues are produced and usually this waste ends up in landfills (Vianna 2011). 
Considering one example in particular, in order to delineate the problem's dimension on textile residues generation, data from the neighborhood of Bom Retiro were focused. This neighborhood is one of the largest commercial fashion centers in Brazil. The confection producers in this region lay down bags of fabric scraps on the streets; afterwards, garbage pickers tear the bags to collect material, leaving a lot of thrown scattered trash (Leite 2011). The region has 1,200 installed confection industries and the collection of textile wastes is poorly structured (CNI - Brazilian National Confederation of Industries, and ABIT - Brazilian Association of Textile and Apparel Industry 2012).

Even with a large number of cooperatives working in the sector, the major part of this waste is not reused or recycled due to issues with logistics, transportation and lack of infrastructure. Thus, the neighborhood of Bom Retiro is the greatest generator of textile waste of São Paulo city. A large amount of this waste are fabrics made of cotton, the most consumed raw textile material in Brazil (nearly $70 \%$ of the total amount) (Costa and Rocha, 2009). The recycling of cotton could bring great benefits to the environment regarding sustainability in the textile and fashion industry. The production and consumption of a simple cotton shirt with $250 \mathrm{~g}(0.55 \mathrm{lb})$ implies in the consumption of $1.7 \mathrm{~kg}$ $(3.75 \mathrm{lb})$ of fossil fuels, $450 \mathrm{~g}(1.0 \mathrm{lb})$ of waste in landfills and the issuance of $4 \mathrm{~kg}(8.82 \mathrm{lb})$ of $\mathrm{CO}_{2}$ to atmosphere. Therefore, the reuse and recycling of fibers provide environmental and economic benefits, for instance (Alwood et al. 2006):

i. Reduction of landfill space. Textiles in landfills present, among other matters, problems such as the remains of synthetic fibers, which take a long time to disintegrate. Also, woolen garments when decomposing produce methane, which contributes to global warming;

ii. Reduction of pressure on natural resources;

iii. Satisfactory results in pollution control and energy economy;

iv. Reduction of spending on raw materials.
One possibility for recycled fibers could be to employ them as reinforcement in composite materials, which in turn could be used in the development of design and fashion products. Composite materials have at least two components or two stages in which physical and chemical properties are clearly different between them. Separately, these constituents maintain their characteristics, but when mixed they form a composite of which properties are impossible to obtain with just one of them. The properties of the composites can be considered as a combination between the properties of the matrix and fibers in addition to the properties of interfaces between the fibers and matrix (Carvalho 2005; Saville, 2007).

In order to find possibilities of recycling, the present study aimed to produce composites employing three different types of thermoset resins (epoxy, polyester orthophthalic and polyurethane) reinforced with recycled textile cotton fibers. Their resistance characteristics were evaluated by means of tensile tests. This study also attempts to conduct a proposal of fashion product application, suggesting a profitable destination different from ordinary discard in landfills.

\section{Methods}

Residues constituted by scraps and cotton yarns were originated by tearing a post-consumption jeans (denim) trouser (M. Officer, model Five Pockets, Brazil), which fabric is from Tavex Corporation company (Americana city, state of São Paulo, Brazil). This fabric was composed of cotton (100\%), heavy weight $12 \mathrm{oz} \mathrm{yd}^{-2}$ (about $410 \mathrm{~g} \mathrm{~m}^{-2}$ ), twill structure (3x1), 67 yarns of warp $\mathrm{x} 41$ yarns of weave per square inch, warp dyed with indigo colorant $(6.5 \mathrm{Ne}$ - where Ne means the number of hanks per pound explaining that 1 hank corresponds to 840 yards or 768 meters per pound or $0.454 \mathrm{~kg}$ - corresponding to 90 Tex (90 g per 1,000 m of yarn), weave (or filling) undyed (9.0 Ne or $65.6 \mathrm{Tex})$, produced from carded yarn by open-end spinning system (Figure 1 and Figure 2a).

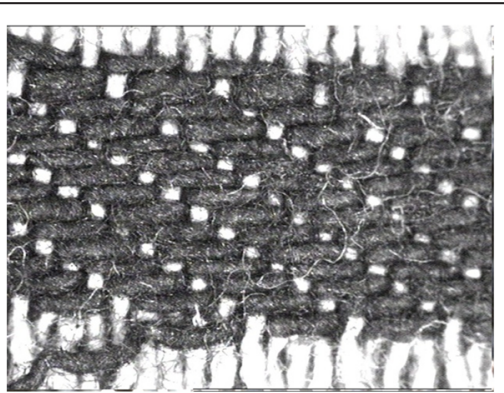

(a)

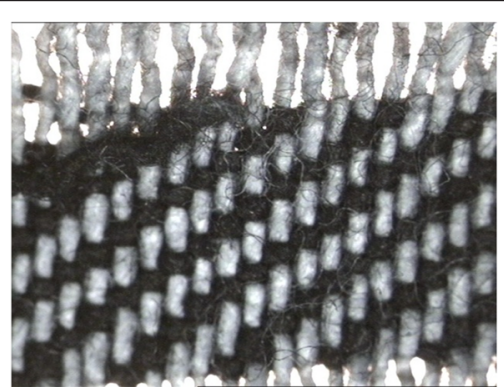

(b)

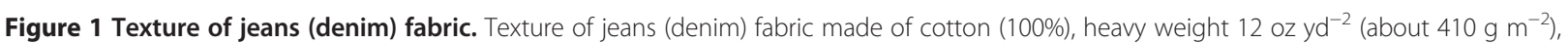
twill structure $(3 \times 1)$. (a) Texture of front of the fabric with a focus on dyed warp ( $\times 32$ magnification) and (b) texture of the back of fabric with a focus on undyed weave (or filling) (×32 magnification). 


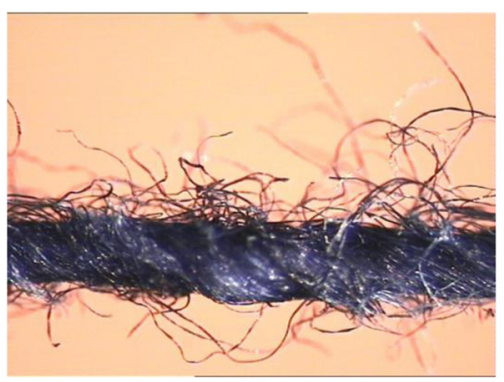

(a)

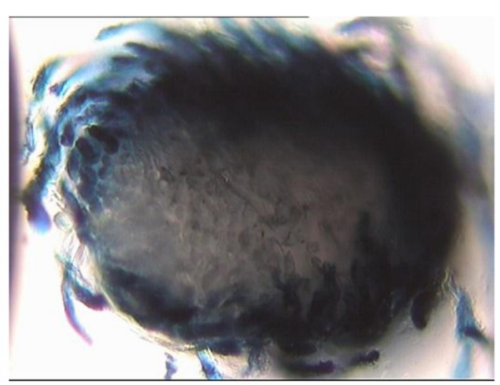

(b)

Figure 2 Longitudinal structure and cross microscopy of cotton open-end warp yarn. (a) Longitudinal structure of cotton open-end warp yarn (magnification $\times 51$ ). (b) Cross microscopy of cotton open-end warp yarn superficially indigo dyed. Inside the presence of undyed cotton fibers is noted (magnification $\times 320$ ).

The trouser was shredded with the aid of scissors into pieces of approximately $5 \times 5 \mathrm{~cm}$ and teared in a blender (model Due Sapore, Britannia, Curitiba/Paraná, Brazil) in order to simulate the process on a small scale of rotary blades of an industrial textile tearing plant. The obtained result is supposed to be similar to that obtained by means of specific tearing machines for processing textile waste. The length of this reinforcement made from recycled cotton fabric varied from 2 to $3 \mathrm{~cm}$.

In order to determine the moisture recovery (or regain) of textile reinforcement, according to the standard ABNT, ISO 139:2005 - Brazilian Association of Technical Standards and International Organization for Standardization 2005 and ISO/TR 6741-4-1987 - International Standards Organization / Technical Report 1987, the obtained textile residues were conditioned for a minimum period of 48 hours at $20^{\circ} \mathrm{C}$ and relative humidity of $65 \%$ (Climatest model M250-RH, Mesdan, Raffa di Puegnago/Brescia, Italy). Subsequently, the amount of moisture was determined by weighing a conditioned sample in an analytical balance (model ED124S, Sartorius, Göttingen, Germany) and then drying was carried out in an oven with forced air circulation (model FD 115, Binder, Tuttlingen, Germany) at $70^{\circ} \mathrm{C}$ until achieving constant weight (overnight) and then the sample was weighted again. The moisture recovery (or regain) is defined as the weight of water (original weight minus dry weight) calculated as a percentage of the dry weight.

For matrix composition of composites the following were employed: i) crystalline epoxy flexible resin BVR 222 (Bonivitta, São Paulo/SP, Brazil) and hardener BVE 0101 (Bonivitta, Brazil); ii) crystalline resin Arazyn 1.0 (polyester orthophthalic) (Artsol, Sumaré/SP, Brazil) and hardener TCatalyst (Moldflex, Brazil); iii) crystalline polyurethane resin of low viscosity Poly-Optic 14 (Moldflex, Brazil) and hardener T-Catalyst (Moldflex, Brazil).

The reinforcement composed by recycled fabric cotton residues was placed at the bottom of a container mold $(\mathrm{H}=9.7 \mathrm{~cm} ; \mathrm{L}=28.5 \mathrm{~cm} ; \mathrm{W}=17.6 \mathrm{~cm})$ and covered by resin.
The specimens (plate composites) consisted of approximately $30 \%$ of reinforcement (apparent volume of $80 \mathrm{~mL}$ ) and the remaining volume of resin (epoxy, polyester and polyurethane), which was approximately $200 \mathrm{~mL}$. Regarding weight, approximately $8.5 \mathrm{~g}$ of residues were employed. The polymeric matrices had density of $1.1 \mathrm{~g} \mathrm{~cm}^{-3}$, near $1: 25$ (weight/weight ratio). The final thickness of the samples was approximately $5 \mathrm{~mm}$. The employed equipment and conditions for composite development were respectively: an open container, temperature near $25^{\circ} \mathrm{C}$ (room temperature), normal atmospheric pressure and 48 hours of resting in order to ensure the proper curing.

Once hardened, the composites were sliced with the aid of a band saw. Ten samples of each of the three different kinds of resins reinforced with fiber and ten samples of each of the three different types of resins without any reinforcement were tested mechanically. The obtained results were compared. Tensile tests were performed according to ABNT, NBR 13041:2004 - Brazilian Association of Technical Standards - Brazilian Standard 2004 (determination of tensile strength and elongation) employing tester machine Instron (model 5569, Norwood, MA, USA).

In order to observe the fabric, microscopies in stereomicroscope (Leica, MS5 model, Germany) coupled to video camera to capture digital images (model VPC 122/CH, 1/2 in. CCD, Vista Protos IV, Wokingham/Berkshire, UK) were performed. For that, the longitudinal yarn structure was affixed onto a cardboard frame and the dispersion and anchoring of the cotton reinforcement in various polymer matrices (epoxy, polyester and polyurethane) were tested, as well as the behavior of the anchoring of the reinforcement in the matrices near the sites of rupture after tester machine tests. The magnifications were 20, 32, 51, 80 and 128 times. The images were captured and processed by the system code 250 Video Analyser 2000 (Mesdan, Italy).

In order to obtain a sectional cross view of the cotton yarn, such was encapsulated in microscopy resin (Technovit 7100, Heraeus, Germany). The cross sections were performed in rotational semi-automated microtome 
(Leica, model RM 2245, Germany) equipped with cut knife type " $\mathrm{C}$ ". The slices were placed on microscope glass slides, flattened with a drop of petrolatum mineral oil (Nujol, Mantecorp, Rio de Janeiro/RJ, Brazil) and covered with glass cover slips. They were analyzed in a biological microscope (Leica, Model BME, Germany) coupled to a video camera to capture digital images (Sony Color Video Camera, model P-55C-DC93, Sony, Shanghai, China). The magnifications were of 128 and 320 times. The images were captured and processed by the system code 250 Video Analyser 2000 (Mesdan, Italy).

Silicone resin RTV-2 (Moldflex, Brazil) and catalyst T (Moldflex, Brazil) in a proportion of $4 \%$ relative to the total volume were employed in order to make the molds for the accessories development (bracelet and ring). Preexisting jewelry gems and bracelets were employed as pre-molds. They were affixed to the bottom of the cardboard container with highly adhesive glue (Loctite - Super Bonder, Henkel Brazil, São Paulo/SP, Brazil. The silicone resin was then mixed with the catalyst and spilled into the cardboard container that was previously sealed with insulating tape to avoid any liquid silicone resin leak.

After five hours, at room temperature and normal atmospheric pressure, the resin was cured, the cardboard container (bottom part) was teared and together the jewelry pre-molds were removed from the negative silicone molds formed. The upper part of these negative molds received a silicone layer of at least one centimeter in order to support and join the necessary negative molds to produce gems and bracelets positive shapes. The bracelet was made of epoxy resin reinforced with textile fibers. The ring gem had the same material as the bracelet, however a small portion of cut golden metalized ribbon was added, in order to provide a glitter effect.

\section{Results and discussion Cotton recycled reinforcement}

The analysis of longitudinal yarn structure aimed to confirm the production process of the yarn employed in this study, due to the fact that denim can be produced through a ring spinning system or rotor spinning (open-end) (Figure 2a). This last one is the most common system for producing yarn for denim weaving (Adanur, 2001; Kaswell 1963).

The rotor spinning, also known as open-end spinning, is used for wiring very short length fibers and it is a generic term for the production of yarn from staple fibers. The term can be employed for any method in which the tape or roving is opened or separated into its individual fibers or tufts, and then reconstituted in the spinning device to form the yarn.

Originally, denim was only made of cotton. Afterwards, this fabric started to be made also with a blend of cotton and polyester, despite the fact that the dyeing of polyester or blended warp is more difficult than $100 \%$ cotton warp. However, the employment of polyester fiber is often as manner to reduce the final cost of the product (Adanur, 2001).

By means of cross section microscopies (Figure 2b), which were compared with reported cotton cross microscopy (Mesdan-Lab 2005), it was possible to identify that the yarn employed in this study is of $100 \%$ cellulosic cotton natural originate, since it is possible to observe in the microscopy the typical transversal shape of cotton fiber with the lumen (small orifice, characteristic of natural fibers) inside it. Similarly, the same was observed for the various fibers composing the cotton yarn (which can be also a cable composed of more than one yarn), the main raw material employed for the production of denim fabric. The indigo dye does not have high affinity for the cotton. As a result, the dying is only superficial on warp yarns, forming a blue ring and leaving a white core, leading to a low fabric color fastness under friction (Marsh et al., 2003).

According to Adanur (2001), the open-end is a process notably employed to produce denim yarn. The open-end yarns are cheap and rustic for not passing through machines that add a sophisticated finishing, such as textile laminating and combing machines, differing, for example, from the ring spinning process where a set of parallelized fibers is well twisted so there is high cohesion and strength. Additionally, in open-end spinning, the individual fibers are not uniformly arranged in the produced yarn as in the spinning ring produced yarn. In an open-end spinning yarn most of the fibers are parallel, but with some intersections and some irregular fibers surrounding the main cable (Fabriclink - Fabric University 2012).

The longitudinal view of the cotton yarn employed in the present study (Figure 2a) shows that it was produced by an open-end process, since it is irregular and with a large number of fibrils, various thinner loose fibers throughout the yarn, presenting also some intersections between themselves and containing some irregular fibers surrounding the main cable.

According to Saville (2007) and Kaswell (1963), the percentage of moisture recovery (or regain) of cotton fiber is around $8.5 \%$. However, after performing this test with 3 replicates, it was found that for the recycled textile reinforcement employed in this study, the values were $9.1 \%, 9.4 \%$ and $10.0 \%$, resulting in $9.5 \pm 0.5 \%$ (average and standard deviation). The accuracy of the analysis is demonstrated by the variation coefficient of only $5 \%$.

Thus, probably the denim fabric employed in the present study was subjected during its production to a chemical treatment to confer it a softer touch, which at the same time increased its hydrophilicity and, possibly, its affinity to the indigo dye. As a hypothesis, the denim fabric may have been subjected to mercerization in the secondary stage of textile processing. The process of mercerizing consists in applying 
cold concentrated caustic soda (sodium hydroxide - $\mathrm{NaOH}$ ) on the tensioned fabric. The caustic soda reacts with the cellulose fibers of the cotton causing a swelling, leaving them with a more rounded profile and decreasing the amorphous regions of the cellulose. The regain of mercerized cotton is approximately from 10 to $12 \%$ (Saville, 2007; Kolpak et al. 1978).

Microscopic transversal examinations of the fibers with magnification of 500x or more allow to determine if the cotton fibers are mercerized or not (Saville, 2007; Kaswell 1963). In the case of the fabric employed in this study, in the eventual case of mercerization process, it possibly would not be applied primarily on the fibers, but directly on the tensioned fabric in the secondary stage of textile processing. The carried out optical transversal microscopies, such as shown in Figure $2 b$, presented transversal profiles compatible to that expected to non mercerized cotton. However, the observation aforementioned cannot be conclusive, since for that the ideal would be to compare the obtained microscopy images with pre-existing patterns (before and after mercerization process) of the same cotton fibers employed for producing the denim fabric employed in this study. On the other hand, the mercerization employ for denim cotton fabric manufacturing is not usual, because it is a prolonged process that requires specific machinery (Santanaense 2014).

As previously mentioned, probably the denim employed in the present study has not been subjected to mercerization process. Nevertheless an example of premium mercerized denim was introduced in the market in 2012 by Santana Textiles manufacturer (Brazil), owner of "Loco Serious Denim" brand (Santana Textiles 2014). This mercerized denim line was called "Absynto" (100\% cotton, twill right structure $3 \mathrm{x} 1$, width: $1.62 \mathrm{~m}$, weight: $10.80 \mathrm{oz} \mathrm{yd}^{-2}$, color: intense blue, finishing: flat) (Bergamasco 2012).

Another more plausible possibility is that, regardless of being or not mercerized, the denim fabric has received in tertiary or late stage of processing, a cellulase enzyme treatment, which provided a controlled hydrolysis or change of the structure of cellulose molecules - the main cotton constituent component (Basra and Malik 1984). Cellulases are able to make cotton fabrics smoother and softer, degrading the surface fibers (loose fibers and microfibrils), conferring also a stone washed appearance (or the aspect of "wear after washings") in jeans (Ferrante 2011; Wadaa et al. 2010).

At last hypothesis, detergents with alkaline $\mathrm{pH}$ formulations are normally used to launder clothes (Nascimento and Martins 2006). In this way, taking in account that in this study a post-consumption trouser made of denim was employed, the cotton fibers of this fabric could be affected by exposure to this alkalinity after repeated washings in alkaline $\mathrm{pH}$ condition.

Nonetheless, according to the obtained regain value observed it is possible to infer that the fabric, which originates the textile reinforcement employed in this study, has received a treatment during its manufacture, which increased the cotton hydrophilicity, meaning also that the crystallinity of cellulose structures were diminished and the amorphous ones were increased (Reddy and Yang 2005).

\section{Composites production and analysis}

Firstly, it is worth pointing that despite the low values of tenacity and modulus presented in Table 1 for epoxy resin, according to information provided by the supplier (Bonivitta, Brazil), this resin is $100 \%$ epoxy resin, since epoxy is a designation of a large family of resins. There are different types of epoxy for different kind of applications (with correspondent different degrees of hardness, toughness, cost, etc.). An epoxy or polyepoxide is a thermosetting plastic that hardens when mixed with a catalyst or "hardening" agent. The most common epoxy resins are products of a reaction between epichlorohydrin and bisphenol-A.

Currently epoxy resins are used for a multitude of applications, such as the inner lining packaging of beer, soda and citrus, among others, printed circuit boards, computer motherboards, encapsulation of electronic components, flash drives, industrial floors, surfboards, anticorrosive coatings, powder painting, among other applications that also use epoxy as a base. Thermosetting resins (or thermosets) play an important role in industry due to their high flexibility for tailoring desired ultimate

Table 1 Tensile results obtained in tester machine assays

\begin{tabular}{lllll}
\hline & Maximum load (N) & Tenacity (MPa) & Extension break (mm) & Young's modulus (MPa) \\
\hline Pure epoxy resin & $9 \pm 1(11 \%)$ & $0.09 \pm 0.01(11 \%)$ & $35 \pm 4(11 \%)$ & $0.5 \pm 0.1(23 \%)$ \\
Epoxy resin + cotton fibers & $17 \pm 1(7 \%)$ & $0.16 \pm 0.01(7 \%)$ & $21 \pm 4(17 \%)$ & $1.2 \pm 0.2(13 \%)$ \\
Pure polyester resin & $654 \pm 58(9 \%)$ & $6.5 \pm 0.6(9 \%)$ & $5.6 \pm 0.4(7 \%)$ & $193 \pm 19(10 \%)$ \\
Polyester resin + cotton fibers & $1,379 \pm 72(5 \%)$ & $13.8 \pm 0.7(5 \%)$ & $2.7 \pm 0.3(10 \%)$ & $772 \pm 120(16 \%)$ \\
Pure polyurethane resin & $1,607 \pm 408(25 \%)$ & $16 \pm 4(25 \%)$ & $3.6 \pm 0.5(15 \%)$ & $679 \pm 152(22 \%)$ \\
Polyurethane resin + cotton fibers & $1,618 \pm 427(26 \%)$ & $16 \pm 4(26 \%)$ & $4.0 \pm 0.8(20 \%)$ & $702 \pm 225(32 \%)$ \\
\hline
\end{tabular}

Tensile results obtained in tester machine assays for epoxy, polyester, and polyurethane resin not reinforced with cotton residues and, respectively, composites reinforced with cotton residues. The values are expressed as average, standard deviation and, in parentheses, the coefficient of variation. 
properties, leading to their high modulus, strength, durability, and thermal and chemical resistances as provided by high cross-linking density. There are now several companies worldwide that specialize in formulating products with their own characteristics attending the need of each user (Raqueza et al. 2010).

Ortophtalic unsaturated polyester resins have in their composition phthalic acid, also known as orthophthalic acid, or anhydride, which dissolves itself in alcohol and some other solvents. This type of resin is the most common, because its use is widespread and low cost. The mechanical properties of ortophtalic unsaturated polyester resins are low. These resins can be used in the production of buttons and toilet seats, and can also be used in the production of electronics, such as the manufacture of reactor lamps. Other suggestions for usage are: casting handicraft and decorative objects as panels, stained glass, table tops, jewelry, statues, trophies, casting parts for toilets and toilet seats, soap dishes, trash cans, sinks and towel racks. Along with glass fiber, it can be used in composing construction tiles (manual process), domes and shutters (Poliresinas 2012; Amico 2010).

Polyurethane resin can be defined as any resin resulting from the reaction of diisocyanates (such as toluene diisocyanate) with an amine, phenol or a carboxylic or hydroxylic compound to produce a polymer with free isocyanate groups that can be employed for prototyping applications, protective coatings, potting, casting resins, adhesives, rubbers, foams, and in paints, varnishes and adhesives (Gil 2009; Zia et al. 2007).

In tests, epoxy resin, polyester and polyurethane were used in pure samples and samples reinforced with textile waste (Figure 3 ). According to the results shown in Table 1 in all cases it was observed that the resistance of all materials increased with the addition of textile reinforcement: in the case of composites made from epoxy resin, an increase of approximately 2-fold relative to pure without reinforcement resin tenacity and modulus (respectively from 0.09 to $0.16 \mathrm{MPa}$ and from 0.5 to $1.2 \mathrm{MPa}$ ). For composites made of orthophthalic polyester resin, those ones with fiber reinforcement showed approximately 2 -fold relative to pure resin for tenacity and 3-fold more for module values (respectively from 6.5 to $13.8 \mathrm{MPa}$ and from 193 to $772 \mathrm{MPa}$ ).

Only for polyurethane resin composites the incorporation of textile recycled reinforcement did not imply in significant alterations in tenacity and module values (16 MPa for tenacity and near $700 \mathrm{MPa}$ for Young's modulus). A plausible explanation for this is to consider that the modulus value supplied by the fraction of cotton fiber (reinforcement) not as significant as that one from the pure polyurethane resin (matrix). Taking in account that the cotton fiber modulus ranges from 8.2 to $9.6 \mathrm{GPa}$ (adapted values from Reddy and Yang 2005; Kaswell 1963) and, as a simple approach that the final modulus is proportional to the moduli of constituents (matrix and reinforcement), the resulting modulus of the polyurethane composite would be: $0.96 \times(0.679)+0.04 \times(9.0)=1.011 \sim 1 \mathrm{GPa}$, which is within the error range of the made measurements (Table 1 ).

Thus, the cotton fiber in the proportion that has been employed in relation to the total polyurethane resin, provided only a small increase in the module value, but not as significant as that observed in the composites made with epoxy or polyester resins. It should also be noted that in the preparation of the composite, shattered yarns instead of totally separate cotton fibers were employed. So it is possible to cogitate that the correspondent modulus value for these shattered yarns was inferior to that of isolated cotton fibers.

It was observed that the values of the modulus for the epoxy resin specimens with and without fiber reinforcement are compatible to those for foams (from 0.001 to $0.01 \mathrm{GPa}$ ) and rubbers (from 0.01 to $0.1 \mathrm{GPa}$ ) (UTL - Technical University of Lisbon 2012); while the values of the modules for the samples of orthophthalic polyester resin and polyurethane, with and without reinforcement of fibers, are closer to the ones for polyethylene (from 2.5 to $4.0 \mathrm{GPa}$ ) and nylon as plastic material (from 1.5 to $4.0 \mathrm{GPa}$ ) (Callister 2007).

Nevertheless, it has been noted that the experimental values of moduli shown in Table 1 are smaller than the values of the polyethylene and nylon polymers (engineering plastics). This finding is consistent with the fact that the assayed resins are currently employed in handicrafts and customized production of articles, which normally present smaller resistance values than the routinely applications of engineering plastics. However for fashion or design applications generally high values of resistance parameters are not necessary as in the case of engineering applications, being more relevant the aesthetic appearance.

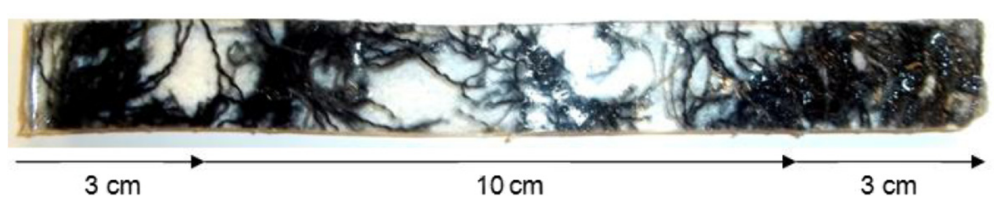

Figure 3 Composite made of polyurethane resin specimen. Strip cut for tensile testing in tester machine with $2 \mathrm{~cm}$ wide, $10 \mathrm{~cm}$ of effective length plus $3 \mathrm{~cm}$ test at each end. 
Withal, the main limitation about incorporation of natural fibers in polymeric materials is relative to the loss of mechanical resistance, many times due to the weak interaction between the polymer and the fiber (Furlan et al. 2012), since the lack of cohesion influences directly the intermaterial tensions. In some cases, composites could have the tendency of forming voids and cracks in the interior and on the surface of its components (Almeida and Rezende 2001).

In the present study, the good adhesion (interface) of the two materials - textile reinforcement and resins was evidenced by the increase of resistance and Young's modulus values (Table 1). It was also possible to verify the good adhesion of all produced composites by the microscopy magnifications (32x) (Figure 4), since torn fibers within the polymer matrix were not found in the places of rupture of the composites after testing in the tester machine, nor cracks or fractures in the composite material as a whole, indicating the proper anchor between reinforcement and matrix. Figure 4 also shows the dispersion of microfibrils inside all three produced composites, being probable that they also aided to increase the good adhesion between matrices and reinforcement.

Taking in account these findings, a first consideration would be that the intersections and some irregular fibers surrounding the main cable of open-end yarn could have promoted the presence of fibrils and microfibrils in the final composite, which probably could increase the good adhesion between matrices and reinforcement. On the other hand, taking into account the previous cited shredding process for textile reinforcement production, it is not possible to ensure the integrity of the yarns originally present in the fabric inside the final composite. Hence, a most plausible hypothesis is to consider that the majority of fibrils and microfibrils were originated from shredding process for production of the textile reinforcement rather than as a consequence of the structure of the open-end yarn.

Concerning the blue colored warp, visible to the human eye or by microscopy magnifications $(32 \mathrm{x})$ (Figure 4), indigo dye diffusion from the yarn surface to the matrices was not observed. It is worthy of mention that the present authors did not find in literature reports about these questions and neither about the employment of composite reinforcement from raw textile material originally composed by colored or not open-end, spinning ring or other kind of yarn.

Aiming to increase the interfacial compatibility between lignocellulosic fibers (hydrophilic) and polymer matrices (usually hydrophobic) in composites, various chemical treatments are usually performed mainly targeting the following modifications on the fiber surface: removal of non-cellulosic components (mainly lignin, hemicellulose and residues), increasing of hydrophobicity and increasing of surface roughness (Carneiro 2013). In addition, it is reported that hydrophilic cellulosic fibers do not adhere well in hydrophobic polymer matrices (Rosario et al. 2011).

In the present study, cotton textile residues were employed as reinforcement. Cotton is a material almost totally constituted by cellulose (Saville, 2007; Kaswell 1963). This molecule has a strong tendency to form inter and intramolecular hydrogen bonds, mainly due to hydroxyl groups. The hydrogen bonds and Van der Waals forces between the various planes are responsible for adding fibrils and microfibrils, allowing it to form an ordered and compact structure which constitutes the crystalline structure of cellulose. However, the hydrogen bonds not only with the cellulosic hydroxyl chain, but also with water. Thus cellulose has great affinity with water, despite being insoluble in it (Sampaio 2013).

The regain (or moisture content) determination is an indirect way to infer the hydrophilicity or hydrophobicity of the material. In the present study, according the obtained regain value it is possible to presume that the fabric, which originated the textile reinforcement employed in this study, has received a treatment during its manufacture, which increased the cotton hydrophilicity, meaning also a reduction of the crystallinity and an increase of the amorphous regions on cellulose structures (Reddy and Yang 2005).

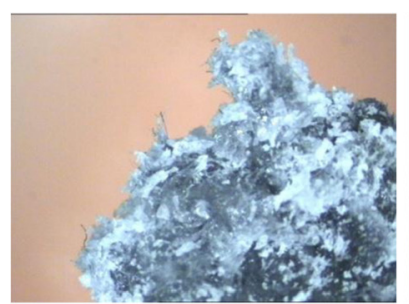

(a)

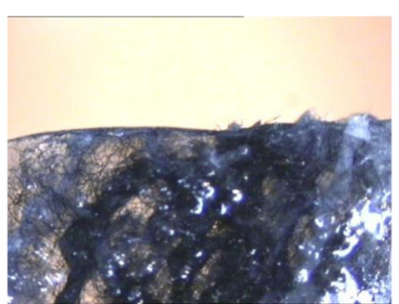

(b)

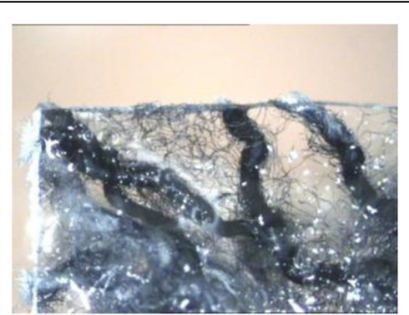

(c)

Figure 4 Magnifications of $\mathbf{3 2}$ times in the site of the composite failure after tester machine assays. These confirm good cohesion between the polymer matrices and textile waste reinforcement. (a) Epoxy resin composite. (b) Orthophthalic polyester resin composite. (c) Polyurethane resin composite. 
Despite of this finding, it was also possible to verify the good adhesion of all produced composites by the microscopy magnifications (32x) (Figure 4). An indicator that the proper anchor occurred between reinforcement and matrix is that neither torn fibers were observed within the polymer matrix in the places of rupture of the composites (after tested in a tester machine), nor cracks or fractures in the composite material as a whole. Figure 4 also shows the dispersion of microfibrils inside all three produced composites, being probable that they also aided to increase the good adhesion between matrices and reinforcement.

Thus, despite contradictory, it is surprising that cotton residues composed by cellulose that received a previous treatment increasing their hydrophilicity, have had such good adhesion with all assayed hydrophobic matrices (epoxy, polyester and polyurethane). Cellulose functioning as composite reinforcement generally receives a treatment for increasing its hydrophobicity, such as plasma (Sampaio 2013).

It should be remarked that the present authors did not find in literature reports about the possible reasons for such contradictory behavior. A hypothesis for this good adhesion could be the tendency of cellulose molecule to form hydrogen bonds and Van der Waals forces between the various planes, including interactions between reinforcement and matrices. Besides this, as cited before, another mechanical factor could be the dispersion of microfibrils inside all three produced composites, being probable that they also aided to increase the good adhesion between matrices and reinforcement.

\section{Sustainable design}

Eco-design or sustainable design is a means to reduce or eliminate environmental impacts generated by the conventional design, replacing products and manufacturing processes for those not harmful to the environment in order to promote sustainable development. Thus, the evaluation of the Life Cycle Assessment (LCA) and product recycling are important factors to be considered. LCA aims an approach of lesser impact on the environment in all the component stages of the manufacturing process, from obtaining raw materials to the disposal of the manufactured product after consumption. LCA takes into account the product durability, its strength and its recycling.

The objective of recycling is to employ residues and reuse them in order to save raw materials and decrease the amount of accumulated waste (Ricken et al. 2008). In addition, according to Scarlato and Pontin (1992) recycling should not be the only way to obtain the raw material, however, it could be an alternative to reduce the accumulation of waste and also as a proposition for environmental education.
A fashion product has a great environmental impact, from conception to disposal. Thus, one of the ways to reduce the environmental impact would be to rethink its entire projective and productive process inserting the concepts of sustainable design, minimizing inputs and outputs during the product life cycle through eco-design (Martins and Sampaio 2006). The sustainable character must be taken into account from the pre-design to production process, generating technological changes and aiming the reduction of environmental impact (Manzini and Vezzoli, 2008).

Broega et al. (2011) suggest how eco-design methodology could be inserted in the Fashion Cycle: through a comprehensive analysis, covering all stages, eco-design is intended to integrate viable possibilities from production until discard of the products. For this purpose, the intervention of public and private institutions would also be required in order to assist with the correct planning for the collecting, management and distribution of unwanted clothing and textiles, which could then be transformed in processes of "partial or total recycling".

The studied materials could be employed in fashion design or other fields of design, especially by their visual aspects and sufficient mechanical characteristics. The present study aimed the production of new composite materials and the analysis of their tensile and aesthetical characteristics in order to collaborate also for the product eco-design methodology based on the recycling of textile wastes, which are extremely abundant in Brazil.

In spite of the employed resins not being recyclable or biodegradable, they were chosen because of the unavailability of purchasing recyclable or biodegradable resins in the Brazilian market. Furthermore, the employment of the chosen resins in this study could provide preliminary data for posterior studies employing biodegradable matrices and consequent biodegradable or recyclable fashion accessories produced from these materials.

Every project involves a creative process, which usually employs a "trial and error" method - from an existing problem possible solutions are applied. During the creative process, the individual - possessing his repertoire and personal experiences, is surrounded by a chaotic situation, subject to endless possibilities and ideas that arise when trying to find solutions to the problem (Ferrari 2011).

Salles (2008) conceptualizes the "documentation process" in the contemporary artistic creation process, basically as the repertoire of stockpiled references and experimentation that the designer uses on the development of creation. According to the same author (Salles 2012), files, documents and records appear quite recurrently in researches developed by those who dedicate themselves to criticism for understanding the processes of creation, i.e., the criticism process, which provides an 


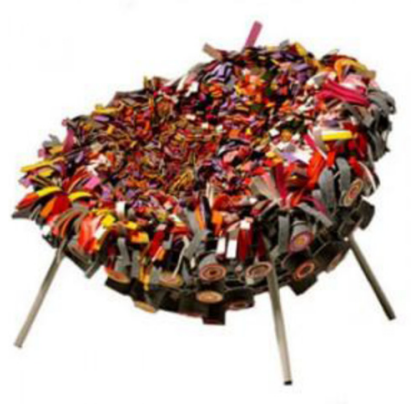

(a)

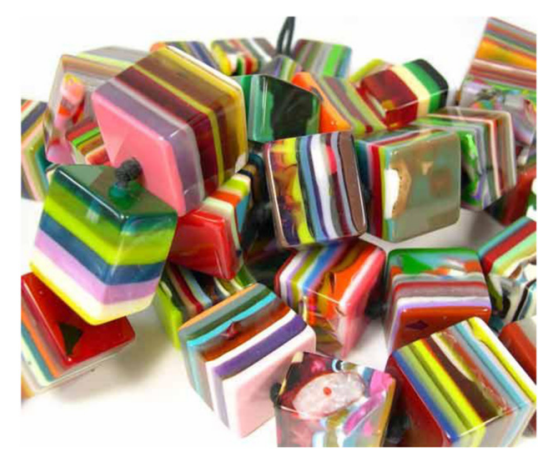

(b)

Figure 5 Design inspirations employing textiles and resins. (a) Armchair from Sushi series of Campana Brothers (Campana Brothers 2012). (b) Resin necklace (Kandinsky collection) from jewelry designer R. Sobral (Sobral 2012).

approach to art from their construction procedures. Documents from creation processes (sketches, notes, audiovisual records, etc.) are taken as material records and indications of the creative route. They are secular portraits of artistic constructions, in the file creation form. Taking in account the recording issue, there are two great constants in these documents that accompany the movement of the production of artworks. They would be common features that are present in the processes under different forms. In general, these documents play two roles during the creative process: storage and experimentation. The artist finds various means for storing information, which act as auxiliaries in the course of artwork completion and nurture the artist and artwork in creation. The storage takes place in the form of notes, diaries, correspondences, etc. Generally the act of creating provisions is always present in the documentation process; however, what is stored and how it is recorded varies from case to case, even by the same artist. Another function, performed by documentation process, is to record the experimentation, making clear the inductive creation nature. In the moment of artwork execution, various kinds of hypothesis are proposed and tested. Private documents are responsible for the artwork development. They are possibilities of artworks. From this perspective, they are experimentation records always present in the creative act, found in drafts, studies, sketches, plans, scripts, models, screenplays, projects, trials, contacts, storyboards. Again, experimentation is common; the singularities arise in the principles that guide the choices. It is not possible to do any kind of generalization about the existence and the consequent use of these different material supports in the various creative processes, even in relation to the employment of such documents by a particular artist. There are variations from one artist to another and from one process to another. It was not exhausted in these listings, the possibilities of creative documentation, but what is being offered here is an overview, from which the peculiarities and individuality of each artist must be worked out case by case. In addressing this diversity, there is a point further questioned when studies about creation are

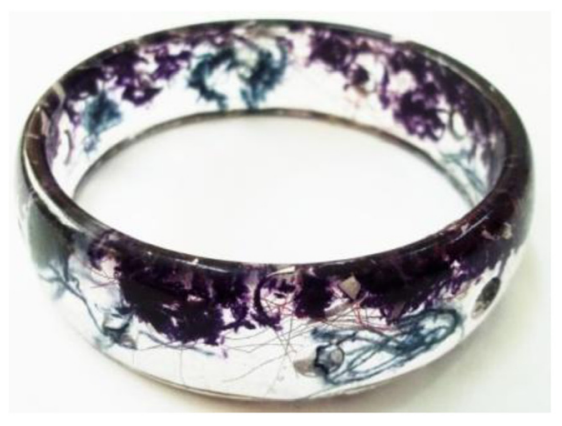

(a)

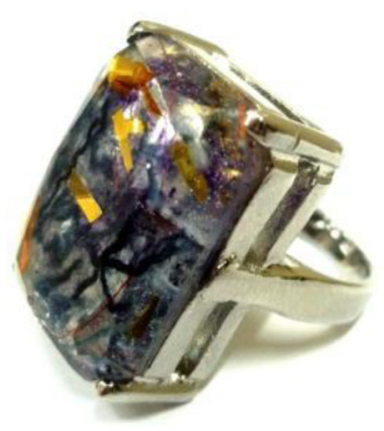

(b)

Figure 6 Examples of fashion design applications made of epoxy resin reinforced with textile fibers. (a) Bracelet. (b) Gemstone ring. 
presented: documents and new technologies. It has been observed that many artists employ the computer as a facilitator of their creative course and, in many cases, not at the expense of other media, which were already used, thus broadening the scope of materiality for analog records.

According to Salles (2012), we are thus faced with ever-expanding archives, seen as a kind of artist notebook, which collects things that interest the artist; it has a website and is also exhibited and published. Apparently private files are made public, whose development can be tracked. It is the storage in its ability to protect an exploration potential for future artworks; records of route (like sketches), but public. Provision and exposure are then indistinguishable.

In the present study, for the creation development of fashion accessories, besides the experimentation with the obtained composite materials, the artworks from two renowned Brazilians designers were used for the present "documentation process". Known as Campana Brothers and R. Sobral, they have employed resins or/and textile wastes to compose their works. Campana Brothers made a series of furniture called Sushi (2000 - 2004) based on the employment of different textures and types of overlapping fabrics (Campana Brothers 2012) (Figure 5a).

The designer Carlos Alberto Rezende Sobral, better known as R. Sobral, is famous for employing different types of resins in their bijoux jewelry creations, as presented in Kandinsky collection (Sobral 2012) (Figure 5b). In such manner, finding that the tensile and aesthetics properties of the composite materials obtained were suitable for the production of these fashion accessories, two simple suggestions that were made for the present study are presented in Figure 6.

It is noteworthy that all obtained composites (from epoxy, polyester and polyurethane resins) are aesthetically similar as shown in Figure 3, as well as the molding and production technique is also similar for the three materials. Thus, for providing examples of fashion applications, taking in account only the aesthetically aspect, any of these composites could be chosen for the confection of presented accessories, since mechanical resistance is not the main aspect of this kind of application.

The composites employed in this study constitute a possibility for the textile reinforcement reduction, because besides possessing strength and cohesion functions, they could be assigned to design or fashion field for the visual attributes they provide. Moreover, they are able to supply specific needs of the consumer market, eager for news, and to furnish the demand for studies of new materials in the textile sector, which lacks specific bibliography that bring together aesthetic and technical analysis covering all production phases of materials, processes, creation and design of the final product.
At last, it is worth noting that the present study did not intend to exhaust the theme of development of fashion products from composite materials taking in account their possibilities of mechanical strength, functionality, aesthetics and recyclability or biodegradability. Hence, new trials and tests should be conducted in future studies aiming the development of new products from these composites.

\section{Conclusions}

The present study showed an alternative for textile recycling by means of production of thermoset composites made from thermoset resins (epoxy, polyester orthophthalic and polyurethane) reinforced with recycled cotton textile residues, on which tensile tests were carried out. The incorporation of $30 \%(\mathrm{v} / \mathrm{v})$ of textile reinforcement resulted in an increase of approximately 2-fold relative to pure resin tenacity and Young's modulus for composites made from the specific epoxy resin employed in the present study; and 2-fold relative to pure resin tenacity and 3 -fold more relative to Young's modulus for composites made of orthophthalic polyester resin. No significant alterations were observed for these parameters in polyurethane resin composites.

All these materials could be employed in fashion design or other fields, especially on account of their visual aspects. Despite the fact that the employed resins are not biodegradable, they were chosen because of the unavailability of purchasing recyclable or biodegradable resins in the Brazilian market. Furthermore the employment of the chosen resins in this study could provide preliminary data for posterior studies employing biodegradable matrices. The present study aimed the production of new composite materials and the analysis of their tensile characteristics in order to collaborate also for the product eco-design methodology based on recycling of textile wastes, which are extremely abundant in Brazil. In addition, the present study aimed to contribute to the scarce literature that joins aesthetic and technical analysis covering all production phases of materials, processes, creation and design of the final product.

\section{Competing interests}

There are no financial or non-financial competing interests (political, personal, religious, ideological, academic, intellectual, commercial or any other) to declare in relation to this manuscript.

\section{Authors' contributions}

WFZ and BMGG carried out laboratory experiments, documentation process of design and artwork, proposition of fashion accessories and drafted part of the manuscript. WD and JBR carried out analyses of experimental results (in technical, statistical, design and artistic aspects), drafted part of the manuscript, reviewed critically the previous and current versions of manuscript, have given final approval of the version to be published and agree to be accountable for all aspects of the study in ensuring that questions related to the accuracy or integrity of any part of the study are appropriately investigated and resolved. All authors read and approved the final manuscript. 


\section{Acknowledgements}

Financial supports from CAPES (Coordination of Improvement of Higher Education Personnel - Brazilian Education Ministry), FAPESP (Sao Paulo Research Foundation) and CNPq (Brazilian National Council for Scientific and Technological Development) are gratefully acknowledged.

Received: 29 April 2014 Accepted: 22 July 2014

Published online: 20 April 2015

\section{References}

ABNT, ISO 139:2005 - Brazilian Association of Technical Standards and International Organization for Standardization. (2005). Têxteis - Atmosferaspadrão para condicionamento e ensaio ("Textiles - Standard atmospheres for conditioning and testing"). São Paulo, SP, Brazil: ABNT.

ABNT, NBR 13041:2004 - Brazilian Association of Technical Standards - Brazilian Standard. (2004). Nãotecido - Determinação da resistência à tração e alongamento - Método de tiras e Grab ("Nonwoven - Determination of tensile strength and elongation - Strip and Grab Methods"). São Paulo, SP, Brazil: ABNT.

Adanur, S. (2001). Handbook of Weaving. Lancaster, PA, USA: Technomic.

Almeida, M, \& Rezende, M. (2001). Interlaminar shear strength of composites with epoxy resin with different arrangement of fibers in the presence of voids. Polímeros, 1(4), 182-189. doi: 10.1590/S0104-14282001000400008.

Alwood, J, Laursen, SE, Rodríguez, CM, \& Bocken, NMP. (2006). Well dressed? The present and future sustainability of clothing and textiles in the United Kingdom. London, UK: University of Cambridge - Institute for Manufacturing.

Amico, SC. (2010). Vegetable fibers as multifunctional materials. Matéria (Rio de Janeiro), 15(2), 355-363. doi: 10.1590/\$1517-70762010000200037.

Basra, AS, \& Malik, CP. (1984). Development of the cotton fiber. International Review of Cytology, 89, 65-113. doi: 10.1016/S0074-7696(08)61300-5.

Bergamasco, C. (2012). Jenswear volta com tudo nessa temporada ("Jeanswear come back up in this season"). 17 April 2012. http://gofw.com.br/vestuario/ janswear-volta-com-tudo-nessa-temporada. Accessed 12 June 2014.

Broega, AC, Carvalho, C, \& Moraes, C. (2011). Methodology of eco-design in the fashion cycle: reuse and recycling of wasted clothing. In Proceedings of the $\mathrm{VI}$ International Congress of Design Research (CIPED), Oct. 10-12, 2011. Lisbon, Portugal: Calouste Goulbekian Foundation.

Callister, WD, Jr. (2007). Materials Science and Engineering (7th ed.). New York, USA: John Wiley \& Sons, Inc.

Campana Brothers. (2012). Fernando and Humberto Campana - Sushi collection armchair. http://campanas.com.br/. Accessed 03 December 2012.

Carneiro, MRD. (2013). Plasma treatment of coconut fibers for obtaining nanofibers and producing phb matrix composites (Graduation final paper in Materials Engineering). Rio de Janeiro (RJ) - Brazil: Polytechnical School. National University of Rio de Janeiro (UFRJ).

Carvalho, FR. (2005). Composites of sisal fibers for use in reinforcement of wooden structures. PhD Thesis in Material Science and Engineering. São Carlos: Polytechnical School, Institutes of Physics and Checmistry. University of São Paulo (USP).

$\mathrm{CNI}$ - Brazilian National Confederation of Industries, \& ABIT - Brazilian Association of Textile and Apparel Industry. (2012). Têxtil e confecção: inovar, desenvolver e sustentar ("Textile and clothing: innovate, develop and sustain"). Brasília, DF, Brazil: CNI.

Costa, ACR, \& Rocha, ERP. (2009). Panorama da cadeia produtiva têxtil e de confecções e a questão da inovação ("Overview of the textile and apparel supply chain and the question of innovation"). BNDES Setorial, 29, 159-202.

Fabriclink - Fabric University. (2012). Yarn facts: ring spinning. http://www. fabriclink.com/university/yarnfacts.cfm. Accessed 08 December 2012.

Ferrante, E. (2011). Biotechnology applied to textile industry. http://textileindustry.ning. com/profiles/blogs/biotecnologia-aplicada-a-6. Accessed 05 December 2012.

Ferrari, DOA. (2011). The comparative study between the criative process in the architechture and in the jewellery emphasizing the creations of Frank Gehry (Master Science Dissertation in Architecture and Urbanism). São Paulo (SP) - Brazil: College of Architecture and Urbanism of University of São Paulo.

Furlan, LG, Duarte, UL, \& Mauler, RS. (2012). Evaluation of oat-reinforced polypropylene composite properties. Química Nova, 35(8), 1499-1501. doi: 10.1590/S0100-40422012000800002.

Gil, L. (2009). Cork composites: a review. Materials, 2, 776-789. doi: 10.3390/ ma2030776.

ISO/TR 6741-4-1987 - International Standards Organization / Technical Report. (1987). Textiles - Fibres and yarns - Determination of commercial mass of consignments- Part 4: Values used for the commercial allowances and the commercial moisture regains. Switzerland, Geneva: ISO.

Kaswell, ER. (1963). Wellington Sears Handbook of Industrial Textiles. Cambridge, USA: Massachusetts Institute of Technology (MIT) and Wellington Sears Company.

Kolpak, FJ, Weih, M, \& Blackwell, J. (1978). Mercerization of cellulose: 1. Determination of the structure of mercerized cotton. Polymer, 19(2), 123-131. doi: 10.1016/0032-3861(78)90027-7.

Leite, F. (2011). Bom Retiro Quer Limpeza - Funcionários das Centenas de Pequenas Confecções da Região Depositam nas Ruas Sacos com Retalhos de Tecido (Bom Retiro wants cleanliness - workers of hundreds of small confections in this region are depositing in the streets bags with fabric scraps). 29 September 2011. http://textileindustry.ning.com/forum/topics/bom-retiro-quer-limpeza. Accessed 4 Jan 2012.

Manzini, E, \& Vezzoli, C. (2008). O desenvolvimento de produtos sustentáveis: os requisitos ambientais dos produtos industriais ("The development of sustainable products: environmental requirements of industrial products") (1st ed.). São Paulo, SP, Brazil: EDUSP.

Marsh, G, Trynka, P, \& Marsh, J. (2003). Denim: l'épopée illustrée d'un tissu de legend ("Denim: illustrated epic of a legendary fabric"). Paris, France: Editions Du Collectioneur.

Martins, SB, \& Sampaio, CP. (2006). Ecodesign e design sustentável: proposta de método para um workshop ("Ecodesign and sustainable design: a methodology proposal for a workshop"). In Proceedings of the 7th Brazilian Congress of Research and Development in Design (P\&D), Aug. 7-9, 2006. Curitiba, PR, Brazil: Centro Universitário Positivo (Unicenp).

MDIC - Brazilian Ministry of Development, Industry and External Trade, \& ABIT Brazilian Association of Textile and Apparel Industry. (2011). MDIC e ABIT realizam pesquisa inédita sobre perfil do consumidor de vestuário ("MDIC and ABIT conduct original research about apparel consumer profile"). 08 November 2011. http://www.mdic.gov.br/sitio/interna/noticia.php?area=1\&noticia=11095. Accessed 13 January 2014.

Mesdan-Lab. (2005). Manuale d'uso e manutenzione ("Operating instructions and maintenance"): Video Analyser 2000, Microlab Advance, Macrolab Advanced (1st ed.). Raffa de Puegnago, BS, Italy: Mesdan S.p.A.

Nascimento, WCA, \& Martins, MLL. (2006). Production of proteases by Bacillus sp. SMIA-2 grow on whey and corn steep liquor and compatibility of the enzyme with commercial detergents. Food Science and Technology (Campinas), 26(3), 582-588. (2006) .doi: 10.1590/S0101-20612006000300016.

Poliresinas. (2012). Resinas poliéster insaturadas ("Unsaturated polyester resins"). Poliresinas Indústria e Comércio de Resinas Ltda. São Bernardo do Campo/ SP, Brazil. http://www.poliresinas.com.br/resinas-poliester-insaturadas.html. Accessed 09 December 2012.

Queiroz, LL. (2003). Urban wastes and the issue of ecodesign: the relevance of biodegradable plastic (Master Science Dissertation in Design). Rio de Janeiro (RJ) - Brazil: Pontifical Catholic University of Rio de Janeiro.

Raqueza, JM, Deléglisea, M, Lacrampea, MF, \& Krawczaka, P. (2010). Thermosetting (bio) materials derived from renewable resources: A critical review. Progress in Polymer Science, 35(4), 487-509. doi: 10.1016/j.progpolymsci.2010.01.001.

Reddy, N, \& Yang, Y. (2005). Properties and potential applications of natural cellulose fibers from cornhusks. Green Chemistry, 7, 190-195. doi: 10.1039/B415102J.

Ricken, LC, Pozza, PP, \& Teixeira, JA. (2008). Ecodesign: escolha de materiais visando sustentabilidade e processos de fabricação ("Ecodesign: choice of materials aiming sustainability and manufacturing processes"). In Proceedings of the 8th Brazilian Congress of Research and Development in Design (P\&D), Oct. 8-11, 2008. São Paulo, SP, Brazil: Associação de Ensino e Pesquisa de Nível Superior de Design do Brasil.

Rosario, F, Pachekoski, WM, Santos, SF, Savastano, H, Jr, \& Casarin, SA. (2011) Virgin and recycled polypropylene composites reinforced with Sisal byproduct. Polímeros, 21(2), 90-97. doi: 10.1590/S0104-14282011005000021.

Salles, CA. (2008). Crítica Genética: fundamentos dos estudos genéticos sobre o processo de criação artística ("Genetic Criticism: Foundations of genetic studies about the process of artistic creation") (3rd ed.). São Paulo, SP, Brazil: EDUC.

Salles, CA. (2012). Arquivos nos processos de criação contemporâneos ("Files in contemporary creation processes"). In Proceedings of the National Association of Researchers in Plastic Arts, Sep. 24-29, 2012. Rio de Janeiro, RJ, Brazil: Associação Nacional de Pesquisadores em Artes Plásticas.

Sampaio, JA. (2013). Characterization of plasma treated cellulose fibers (Graduation final paper in Materials Engineering). Rio de Janeiro (RJ) - Brazil: Polytechnical School. National University of Rio de Janeiro (UFRJ).

Santana Textiles. (2014). Loco serious denim - collection rigid - Absynto. http://www.santanatextiles.com/locofiltro.php?t=5. Accessed 12 June 2014. 
Santanaense. (2014). Glossário - Mercerização ("Glossary - Mercerization"). http:// www.santanense.com.br/sportswear/glossario/1/M. Accessed 12 June 2014. Saville, BP. (2007). Physical testing of textiles. Cambridge, UK: The Textile Institute and Woodhead Publishing Limited.

Scarlato, FC, \& Pontin, JA. (1992). Do nicho ao lixo: sociedade, ambiente e educação ("From the cradle to grave: society, environmental and education") (18th ed.). São Paulo, SP, Brazil: Atual Editor.

SINDITEXTIL - Union of Spinning and Weaving Industries of the State of São Paulo - Brazil. (2012). Retalho Fashion é destaque de evento na Rio + 20 ("Retail Fashion is featured event at Rio +20"). 20 June 2012. http://www.sinditextilsp. org.br/index.php/materias/item/841-retalho-fashion-\%C3\%A9-destaquede-evento-na-rio\%2020. Accessed 13 March 2014.

Sobral, R. (2012). Kandinsky collection - necklace. http://en.sobraldesign.com.br/ \#/undefined/Collections. Accessed 03 December 2012.

UTL - Technical University of Lisbon. (2012). Propriedades Mecânicas de Metais, Cerâmicos e Polímeros ("Mechanical Properties of Metals, Ceramics and Polymers"). http://disciplinas.ist.utl.pt/qgeral/mecanica/MetCerPol.pdf Accessed 11 November 2012.

Vianna, F. (2011). Personal interview of Eng. Francisco Vianna from LOGA - Environmental Logistics of São Paulo S. A. http://www.loga.com.br/. 08 August 2011.

Wadaa, M, Ikeb, M, \& Tokuyasub, K. (2010). Enzymatic hydrolysis of cellulose I is greatly accelerated via its conversion to the cellulose II hydrate form. Polymer Degradation and Stability, 95(4), 543-548. doi: 10.1016/j. polymdegradstab.2009.12.014

Zia, KM, Bhatti, HN, \& Bhatti, IA. (2007). Methods for polyurethane and polyurethane composites, recycling and recovery: a review. Reactive and Functional Polymers, 67(8), 675-692. doi: 10.1016/j. reactfunctpolym.2007.05.004

\section{Submit your manuscript to a SpringerOpen ${ }^{\circ}$} journal and benefit from:

- Convenient online submission

- Rigorous peer review

- Immediate publication on acceptance

- Open access: articles freely available online

- High visibility within the field

- Retaining the copyright to your article

Submit your next manuscript at $>$ springeropen.com 